\title{
Myocardial strain analysis as a non-invasive screening test in the diagnosis of stable coronary artery disease
}

\author{
Nehzat Akiash', Mohammad Mohammadi ${ }^{*}$, Hoda Mombeini ${ }^{1}$ and Akbar Nikpajouh²
}

\begin{abstract}
Background: Coronary artery disease (CAD) is one of the most prevalent diseases around the world; however, finding the best noninvasive, low-cost, and more easily accessible test for its screening has been a challenge for several years. Eighty-nine patients suspected of stable CAD underwent 2D-speckle-tracking echocardiography (2DSTE) at resting position and offline longitudinal myocardial strain analysis, followed by coronary angiography. The correlation of the global longitudinal strain (GLS) and territorial longitudinal strain (TLS) with significant CAD (70\% and more stenosis in at least one coronary artery) was then evaluated.

Results: The statistical analysis showed a significant correlation between low GLS and significant CAD ( $P=0.0001)$. The results also showed a significant correlation between low TLS and significant CAD in the left and right coronary artery territories. The optimal cut-off point of GLS for the detection of significant CAD was -19.25 , with a sensitivity of $76.5 \%$ and specificity of $76.6 \%$.
\end{abstract}

Conclusion: This study confirmed the usefulness of 2DSTE myocardial strain analysis in diagnosis of CAD for detecting the affected coronary arteries using GLS and SLS.

Keywords: CAD, Strain analysis, 2D-STE, non-invasive tests, Echocardiography

\section{Background}

Coronary artery disease (CAD) is one of the most prevalent disorder that is further growing as the population grows old. Chest pain accounts for six million emergency room visits in the USA every year and leading to ten million stress tests and one million coronary angiographies [1,2].

Finding the best noninvasive screening test for CAD is still a matter of debate [3]. Exercise tests are the first-line screening for most patients, but lower sensitivity and specificity sometimes limited them in CAD diagnosis even combined with myocardial perfusion imaging or echocardiogram. Furthermore, these tests are not practical for patients with mobility issues $[4,5]$. On the other hand,

\footnotetext{
* Correspondence: dr.m.mdi@gmail.com

'Atherosclerosis Research Center, Ahvaz Jundishapur University of Medical Sciences, Ahvaz, Iran

Full list of author information is available at the end of the article
}

myocardial perfusion scans and CT angiography are expensive and pose the risk of radiation exposure [5].

Myocardial strain analysis with 2D-speckle-tracking echocardiography (2DSTE), which is performed at resting position, offers valuable information about myocardial fiber changes in different types of myocardial diseases [6-8]. Speckle tracking consists of analyzing the motion of the speckles within selected segments of the myocardium, combined with an analysis of myocardial segment changes in strain is a state-of-the-art method for the diagnosis of subclinical diseases. Strain changes occur in three dimensions: longitudinal, radial, and circumferential. True strain as myocardial lengthening and shortening is a complex threedimensional deformation, also encompassing rotation. What is measured with strain by echo is a substitute for this complex deformation [8, 9]. Despite Doppler tissue imaging (DTI), 2DSTE is not influenced by noises or adjacent segment tethering and is also not angle-dependent [10-13].

\section{Springer Open}

(- The Author(s). 2021 Open Access This article is licensed under a Creative Commons Attribution 4.0 International License, which permits use, sharing, adaptation, distribution and reproduction in any medium or format, as long as you give appropriate credit to the original author(s) and the source, provide a link to the Creative Commons licence, and indicate if changes were made. The images or other third party material in this article are included in the article's Creative Commons licence, unless indicated otherwise in a credit line to the material. If material is not included in the article's Creative Commons licence and your intended use is not permitted by statutory regulation or exceeds the permitted use, you will need to obtain permission directly from the copyright holder. To view a copy of this licence, visit http://creativecommons.org/licenses/by/4.0/. 
Subendocardial myocardial fibers are the most sensitive areas to ischemia, so that measuring the changes in their length and figures can provide the most sensitive indicator of ischemia arising from CAD [14, 15] [1, 16]. This study evaluates the sensitivity and specificity of this new modality for screening CAD in patients suspected of having stable angina pectoris.

\section{Methods}

\section{Study design}

The exclusion criteria were considered as following age below 18 years, a left ventricular ejection fraction $<50 \%$ based on the 2D echocardiography, a prior history of CAD, myocardial infarction, percutaneous coronary intervention (PCI) or coronary artery bypass graft, acute coronary syndrome (ACS), congestive heart failure, any wall motion abnormality, more than mild valvular heart disease, ventricular conduction disturbances, pathological Q waves in resting ECG, atrial fibrillation, poor image quality for assessing all the segments by speckle tracking, and having refused coronary angiography.

\section{Standard echocardiography and speckle-tracking strain} analysis

Upon admission, the patients' complete medical history was taken, and they underwent a physical examination and 2D echocardiography for speckle-tracking evaluation and conventional transthoracic echocardiography at resting position using Vivid E9 ultrasound (USA, GE Ultrasound). Echocardiographic studies were performed and analyzed by a trained fellow of advanced echocardiography who was blinded to the coronary angiography results.

For longitudinal strain evaluation, three standards (apical two-, three-, and four-chamber) views were recorded from three consecutive beats (Fig. 1) and the offline longitudinal strain analysis was performed using the Automated Function Imaging (AFI) model (GE Ultrasound) by two echocardiologists separately who were expert in strain analysis.

In this method, the LV contour was traced in each view, and after some manual endocardial adjustment, the software automatically gave a longitudinal strain score to each myocardial segment (Fig. 2).

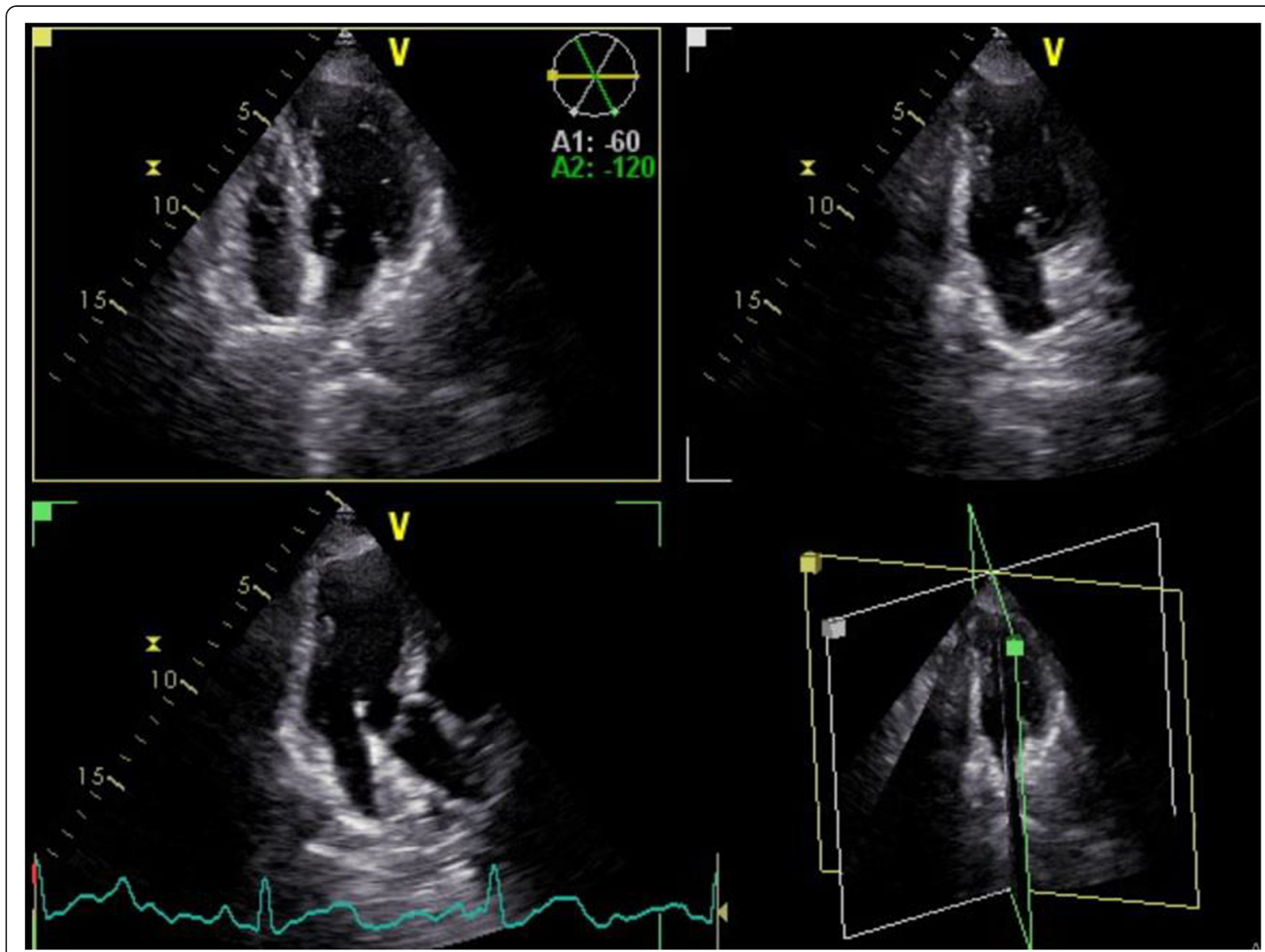

Fig. 1 Three standard views, two-, three-, and apical four-chamber, for evaluation of longitudinal strain 


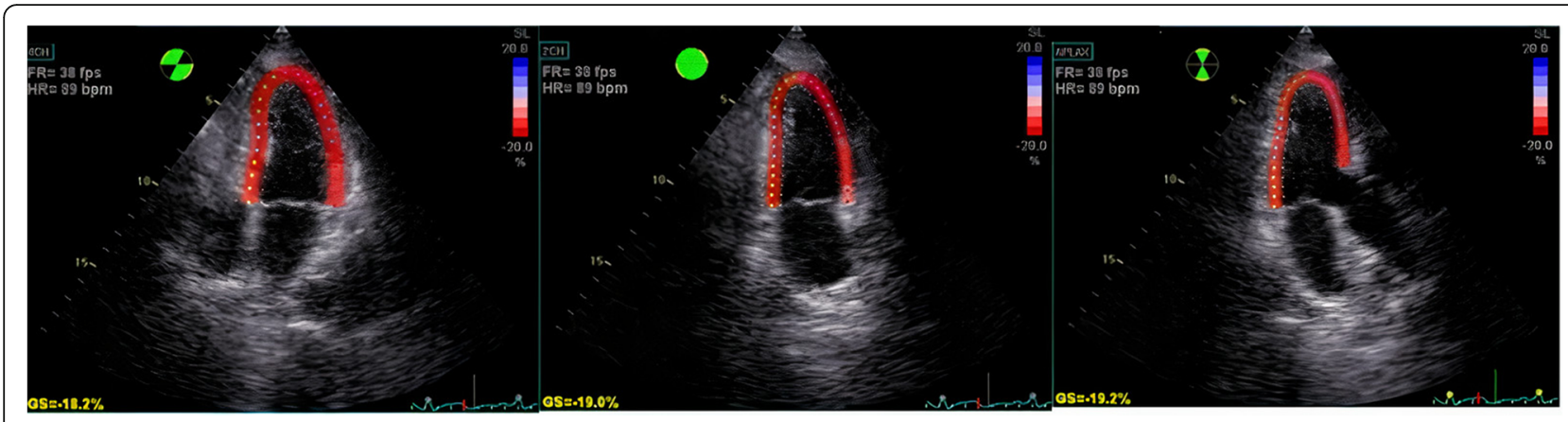

Fig. $\mathbf{2}$ LV contour was traced in each view for evaluation of longitudinal strain score to each myocardial segment

Finally, peak systolic longitudinal strain values were recorded for each segment in the form of 17-segment bull's eye that was labeled as segmental longitudinal strain (SLS). Global longitudinal strain (GLS) was automatically calculated as the mean value of three apical projections (Figs. 3 and 4).

Territorial longitudinal strain (TLS) was calculated for three major coronary arteries (LAD, LCX, and RCA) by the mean value of SLS in segments perfused by each coronary artery. We applied 17-myocardial segment popular pattern which includes 7 segments related to LAD (basal anterior, basal anteroseptal, mid anterior, mid anteroseptal, anthropical, apical septal, apex cap), six segments related to LCX (basal lateral, basal posterior, mid posterior, mid lateral, apicolateral), and six RCA-related segments (basal septal, inferobasal, mid inferior, mid septal, inferoapical).

\section{Coronary angiography}

All the patients underwent coronary artery angiography within 1 week of the echocardiography by an interventional cardiologist, who was blinded to the echocardiography reports. Angiograms were performed via the femoral or radial artery approach, and

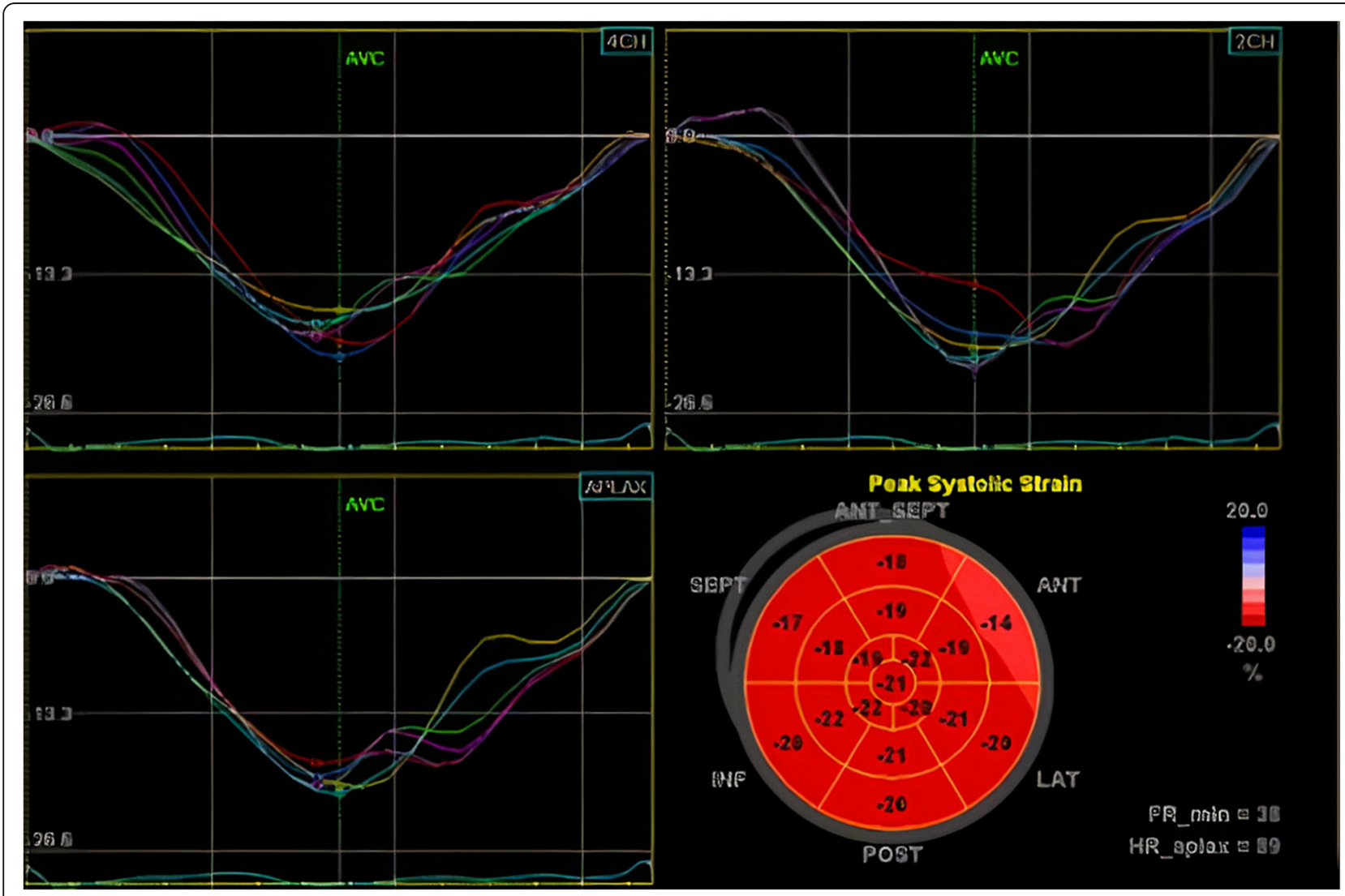

Fig. 3 Bull's eye map of each segment with strain curves 


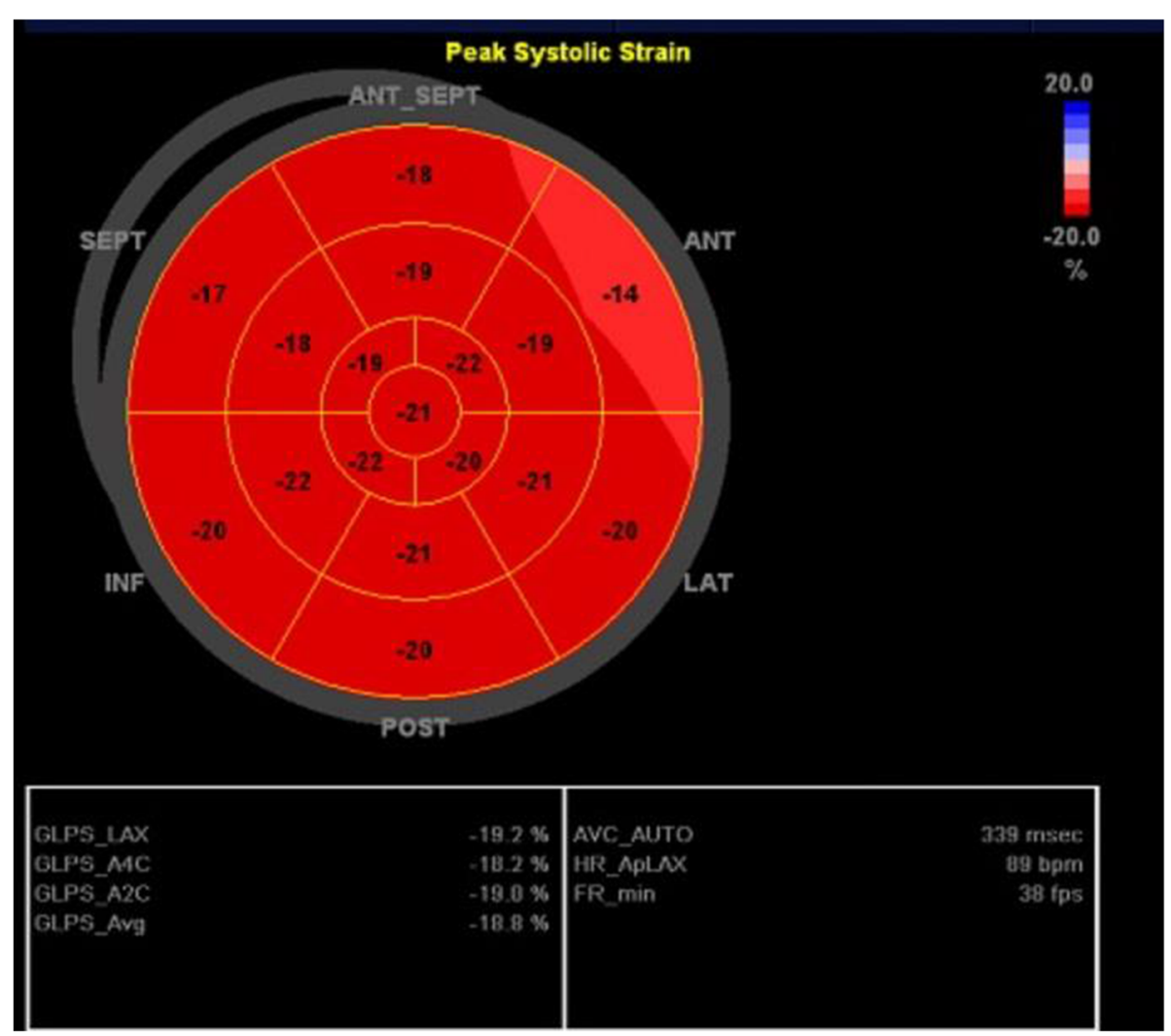

Fig. 4 Bull's eye map of each segment with global longitudinal strain (GLS) of 2, 3, and 4 chamber views and average GLS

at least two projections were made for each coronary vessel. Seventy percent and more stenosis in at least one coronary artery, including the left anterior descending (LAD) and its large branches (i.e., diagonals), the left circumflex coronary artery and its large branches (i.e., obtuse marginal $[\mathrm{OM}]$ branch), and the right coronary artery (RCA), and 50\% and more stenosis in the left main (LM) coronary artery were taken as significant CAD. Stenosis between 50 and $70 \%$ in the coronary arteries (except LM) was taken as moderate $\mathrm{CAD}$, and stenosis less than $50 \%$ was taken as mild CAD.

\section{Statistical analysis}

The results of the 2DSTE and coronary angiograms were statically analyzed in SPSS software (version 25). The Ttest was used to evaluate the correlation between the strain scores and significance of CAD. A ROC curve analysis was performed to predict the cut-off point of GLS for the best sensitivity and specificity for predicting significant CAD.

\section{Results}

Ninety-four patients were finally enrolled in this study. Five of them were excluded due to unsatisfactory image quality for strain analysis. The mean age of 89 patients was 57.3 years, with a range of 34 to 88 years. Fifty-six of them were male $(62.9 \%)$, and 33 (37.1\%) were female. Table 1 represents the detailed demographic data of the patients.

Angiographic findings showed 51 patients (57.3\%) with significant coronary lesions in at least one coronary

Table 1 Patients' characteristics

\begin{tabular}{ll}
\hline Patients' characteristics & Result \\
\hline Age (years) & $57.3(34-88)$ \\
Men & $56(62.9 \%)$ \\
Weight $(\mathrm{kg})$ & $78.68(55-107)$ \\
Height $(\mathrm{cm})$ & $168.14(150-184)$ \\
BMl $\left(\mathrm{Kg} / \mathrm{m}^{2}\right)$ & $27.87(19.7-34.6)$ \\
Smoking & $20(22.5 \%)$ \\
ESRD & $2(2.2 \%)$ \\
Diabetes mellitus & $25(28.1 \%)$ \\
Hypertension & $49(55.1 \%)$ \\
Dyslipidemia & $35(39.3 \%)$ \\
Family history of CAD & $24(27.0 \%)$ \\
\hline
\end{tabular}

Data are expressed as No (\%) or mean (Min-Max)

Abbreviations: $B M I$ body mass index, ESRD end-stage renal disease, $C A D$ coronary artery disease 
vessel, while 21 patients (23\%) had normal coronary arteries with no CAD; details of coronary angiography results are summarized in Table 2.

Table 3 shows the frequency of coronary risk factors in patients with and without CAD, indicating a significant correlation between these risk factors and significant CAD.

The mean GLS was $-16.8 \%$ in patients with significant CAD, $-16.7 \%$ in SVD patients, $-16.8 \%$ in 2 VD group, and $-17.08 \%$ in 3 VD population, which was significantly lower compared to the controls group with normal epicardial coronary arteries $(P$-value $=0.0001)$ (Table 4$)$.

The study findings showed a statistically significant correlation between TLS abnormality and significant lesions in the related coronary artery. Mean TLS of LAD segments was -17.7031 in patients with significant LAD lesions, and it was -20.6676 in patients without significant LAD stenosis $(P$-value $=0.005)$. This correlation was also observed in LCX $(P$-value $=0.016)$ and RCA territory $(P$-value $=0.001)$ (Table 5).

The receiver operating curve (ROC) was used to find the best cut-off point for sensitivity and specificity of GLS in the patients with significant CAD, which was reported as -19.25 with a sensitivity of $76.5 \%$ and specificity of $76.6 \%$. The area under the receiver operating curve [(AUC)] was 0.786 (Fig. 5).

\section{Reproducibility of evidence}

For $10 \%$ of the study population randomly selected, the inter- and intra-observer variability were calculated, and the results fell in the acceptable range. The interobserver and intra-observer variability correlation

Table 2 Coronary angiography results

\begin{tabular}{ll}
\hline LM disease & $3(3.4 \%)$ \\
Significant LAD stenosis & $30(33.7 \%)$ \\
Significant diagonal stenosis & $18(20.2 \%)$ \\
Moderate LAD stenosis & $5(5.6 \%)$ \\
Significant LCX stenosis & $20(22.5 \%)$ \\
Significant OM stenosis & $19(21.3 \%)$ \\
Significant RCA stenosis & $31(34.8 \%)$ \\
Moderate RCA stenosis & $9(10.1 \%)$ \\
Single vessel disease & $16(18.2 \%)$ \\
Two vessel disease & $14(15.7 \%)$ \\
Three vessel disease & $21(23.6 \%)$ \\
Mild CAD & $17(19.1 \%)$ \\
Normal coronary arteries & $21(23.6 \%)$ \\
Significant CAD & $51(57.3 \%)$ \\
\hline Data are expressed as No (\%) & \\
Abbreviations: CAD coronary artery disease, LAD Left anterior descending \\
artery, LCX left circumflex artery, RCA right coronary artery, OM \\
obtuse marginal
\end{tabular}

Table 3 Frequency of coronary risk factors in patients with and without CAD

\begin{tabular}{llll}
\hline Risk factors & Significant CAD & Normal coronary arteries & $P$-value \\
\hline DM & $16(17.97 \%)$ & $6(6.74 \%)$ & 0.052 \\
HTN & $34(38.2 \%)$ & $12(13.48 \%)$ & 0.002 \\
DLP & $24(26.96 \%)$ & $10(11.23 \%)$ & 0.02 \\
FH & $17(19.1 \%)$ & $4(4.49 \%)$ & 0.007 \\
smoking & $15(16.85 \%)$ & $5(5.61 \%)$ & 0.041 \\
\hline
\end{tabular}

Data are expressed as No (\%)

Abbreviations: $C A D$ coronary artery disease, DM diabetes mellitus, HTN

hypertension, DLP dyslipidemia, FH family history of premature CAD

coefficients for GLS and SLS were as follows: Interobserver variability $=0.008 \pm 0.301$ (mean \pm Standard error of mean), Interobserver variability $=0.323 \pm 0.137$ (mean \pm Standard error of mean)

\section{Discussion}

Sub-endocardial fibers are the most sensitive fibers to ischemic events [12]. This study was conducted to prove the correlation between systolic shortening of these fibers in the longitudinal direction and CAD. Biering-Sørensen et al. found that GLS can increase the diagnostic power of exercise tests. Furthermore, they represented a cut-off value for GLS of $-18.4 \%$ with $74 \%$ sensitivity and $89 \%$ specificity for detecting significant CAD [12]. Moreover, Radwan and Hussein compared GLS in patients with percent diameter of $70 \%$ or greater versus others with less than $70 \%$ coronary stenosis, which resulted in statistically significant differences between two groups. Additionally, the cutoff point of $-15.6 \%$ for GLS showed the highest sensitivity and specificity of $93.1 \%$ and $81.8 \%$, respectively [17]. Tsai et al. evaluated GLS, peak segmental longitudinal strain difference, and ratio to peak systolic GLS, which showed lower values in patients with CAD than those with standard coronary angiography. They also showed that using GLS value $>-19 \%$ as a diagnostic tool for CAD with a $74.7 \%$ sensitivity and $80.5 \%$ specificity compatible with the present study's ROC curve results [7]. In confirmation of the previous researches, the present study underscores the significantly lower GLS among patients with significant

Table 4 Mean GLS in respect to CAD severity

\begin{tabular}{lll}
\hline Involvement of coronary arteries & Mean GLS (\%) & $P$-value \\
\hline Significant CAD & $-16.8558 \pm 3.78$ & 0.0001 \\
SVD & $-16.7 \pm 4.07$ & \\
2VD & $-16.8143 \pm 3.39$ & \\
3VD & $-17.085 \pm 3.93$ & \\
NECA & $-20.4857 \pm 2.73$ & \\
\hline
\end{tabular}

Abbreviations: SVD single vessel disease, $2 V D$ two-vessel disease, 3VD threevessel disease, NECA normal epicardial coronary artery 
Table 5 Correlation of TLS and significant CAD in each coronary artery territory

\begin{tabular}{llll}
\hline Coronary artery territories & Number & Mean TLS (\%) & $\boldsymbol{P}$-value \\
\hline LAD segments in patients & & & 0.005 \\
With significant LAD lesion & 37 & -17.7031 & \\
$\quad$ Without significant LAD lesion & 52 & -20.6676 & \\
LCX segments in patients & & & 0.016 \\
With significant LCX lesion & 30 & -15.0267 & \\
Without significant LCX lesion & 58 & -17.35 & \\
RCA segments in patients & & & 0.001 \\
$\quad$ With significant RCA lesion & 31 & -15.5548 & \\
Without significant RCA lesion & 57 & -18.29 & \\
\hline
\end{tabular}

Abbreviations: $C A D$ coronary artery disease, $L A D$ left anterior descending artery, $L C X$ left circumflex artery, $R C A$ right coronary artery, $T L S$ territorial longitudinal strain

CAD. Additionally, the ROC curve analysis illustrated a cutoff point of $-19.25 \%$ with a $76.5 \%$ sensitivity and $76.7 \%$ specificity, which was somewhere between the figures obtained in the three noted studies.

Recently, a few studies sought to evaluate whether there is a relationship between TLS and coronary stenosis. Casper et al. found that TLS may be of great help to localize significant coronary artery stenosis. They reported a threshold of $-19.4 \%,-16.4 \%$, and $-18 \%$ for the TLS in LAD, LCX, and RCA segments, respectively, to predict stenosis in related coronary arteries [18]. On the other hand, Zou et al. demonstrated GLS as a good predictor for diagnosing LM or three-vessel CAD in detecting stenotic coronary arteries [19]. These discrepancies encouraged us to run our study to evaluate further the relationship between coronary stenosis and TLS in given territories. Further analysis showed a statistically significant correlation between low TLS and significant CAD in the LAD, RCA, and LCX territories. These results indicate that strain analysis can be used for screening of CAD in patients with no regional wall motion abnormalities at rest and may also help surmise which coronary artery may have been affected.

As expected, this document supports more frequent conventional coronary risk factors (diabetes mellitus, hypertension, hyperlipidemia, smoking, and premature family history of coronary disease) in CAD patients compared to ones with normal epicardial coronary arteries. On the other hand, the mean age of 57.3 years old in the population study could imply the higher prevalence of young $C A D$ in our society arising from ethnic differences.

\section{Limitations}

Our study population was small, and this study considered only the anatomical severity of coronary stenosis in coronary angiography, but not the functional severity of stenosis or coronary microvascular disease, so incorporating the functional significance of coronary stenosis into anatomical characteristics using FFR is recommended for future studies. Furthermore, the obtained

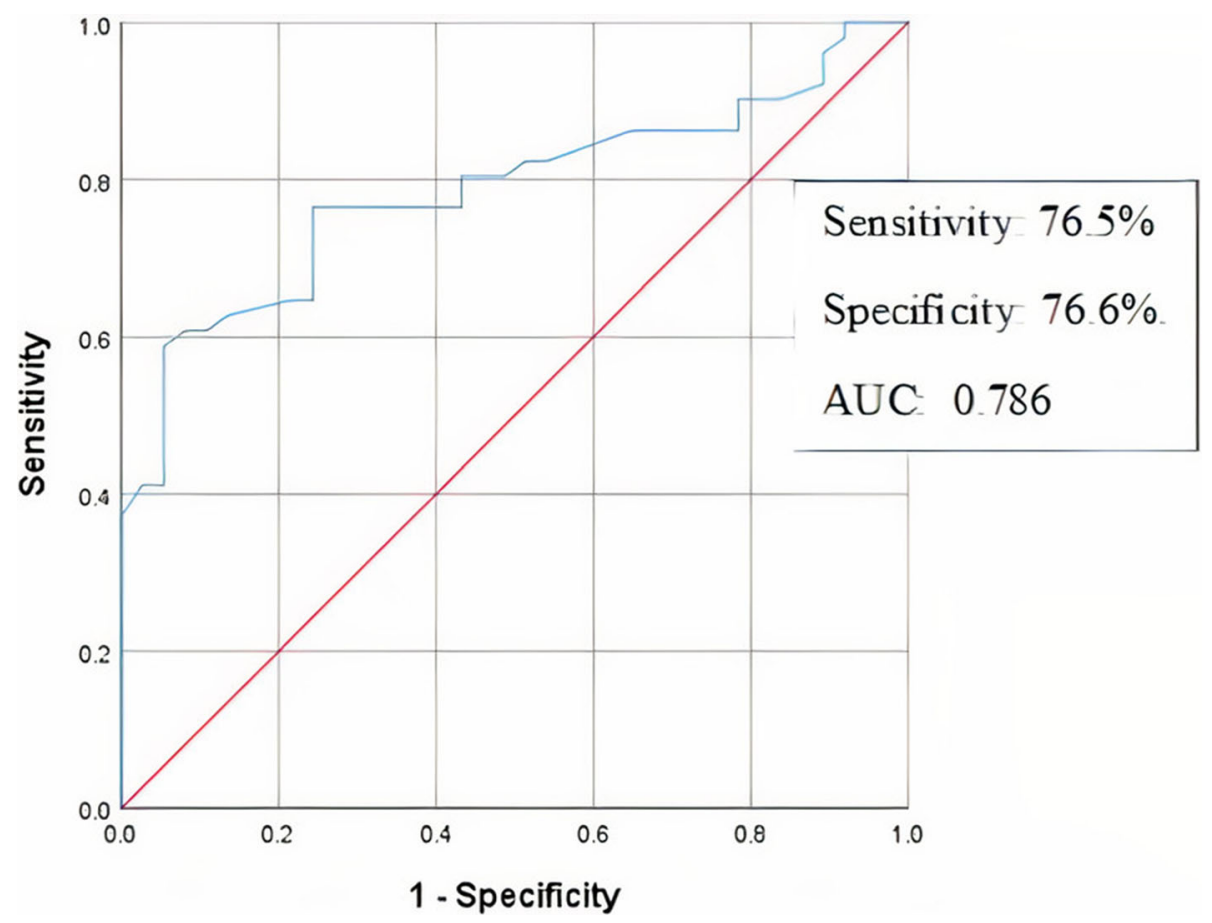

Fig. 5 Receiver operating characteristic (ROC) curve analysis (global longitudinal strain $\geq-19.25$ may be useful to detect coronary artery disease) 
GLS cut-off value for identifying LV ischemia should be validated in studies with a large number of CAD patients.

\section{Conclusion}

This study shows that patients with CAD have lower GLS than others with normal coronary arteries. Additionally, subjects with significant stenosis in a specific coronary artery have less harmful longitudinal strain in the coronary artery territory than others with a patent index coronary artery. These speckle-tracking findings may benefit not only the diagnosis of CAD but also in defining the affected coronary arteries, suggesting GLS and TLS as a presumptive non-invasive tool for coronary stenosis detection.

\section{Abbreviations}

CAD: Coronary artery disease; 2DSTE: 2D-speckle-tracking echocardiography; GLS: Global longitudinal strain; TLS: Territorial longitudinal strain; DTI: Doppler tissue imaging; PCl: Percutaneous coronary intervention; ACS: Acute coronary syndrome; SLS: Segmental longitudinal strain; LAD: Left anterior descending; RCA: Right coronary artery; LM: Left main; BMI: Body mass index; ESRD: Endstage renal disease; LCX: Left circumflex artery; DM: Diabetes mellitus; HTN: Hypertension; DLP: Dyslipidemia; FH: Family history of premature CAD; SVD: Single vessel disease; 2VD: Two-vessel disease; 3VD: Three-vessel disease; NECA: Normal epicardial coronary artery; ROC: Receiver operating curve

\section{Acknowledgements}

We wish to thank all our colleagues in Allied Health Sciences School, Ahvaz Jundishapur University of Medical Sciences.

\section{Authors' contributions}

M.M. conceived the manuscript and revised it. N.A, H.M, and A.K. did the statistical analysis, wrote the manuscript, and prepared the tables and figures. All authors have read and approved the manuscript.

\section{Funding}

None.

\section{Availability of data and materials}

The datasets generated and/or analyzed during the current study are available in the [Pubmed, Web of Science, Scopus, EM Base] repository.

\section{Declarations}

\section{Ethics approval and consent to participate}

The Research Ethics Board approved our study of Ahvaz Jundishapur University of Medical Sciences (IR.AJUMS.REC.1396.866). Written informed consent has been obtained from all patients.

\section{Consent for publication}

Not applicable

\section{Competing interests}

The authors declare that they have no competing interests.

\section{Author details}

${ }^{1}$ Atherosclerosis Research Center, Ahvaz Jundishapur University of Medical Sciences, Ahvaz, Iran. ${ }^{2}$ Rajaie Cardiovascular Medical and Research Center, Iran University of Medical Sciences, Tehran, Iran.
Received: 11 March 2021 Accepted: 13 May 2021

Published online: 25 May 2021

\section{References}

1. Bakhoum SW, Taha HS, Abdelmonem YY, Fahim MA (2016) Value of resting myocardial deformation assessment by two dimensional speckle tracking echocardiography to predict the presence, extent and localization of coronary artery affection in patients with suspected stable coronary artery disease. Egyptian Heart J 68(3):171-179. https://doi.org/10.1016/j.ehj.2016.02. 001

2. Benjamin EJ, Blaha MJ, Chiuve SE, Cushman M, Das SR, Deo R, de Ferranti SD, Floyd J, Fornage M, Gillespie C, Isasi CR, Jiménez MC, Jordan LC, Judd SE, Lackland D, Lichtman JH, Lisabeth L, Liu S, Longenecker CT, Mackey RH, Matsushita K, Mozaffarian D, Mussolino ME, Nasir K, Neumar RW, Palaniappan L, Pandey DK, Thiagarajan RR, Reeves MJ, Ritchey M, Rodriguez CJ, Roth GA, Rosamond WD, Sasson C, Towfighi A, Tsao CW, Turner MB, Virani SS, Voeks JH, Willey JZ, Wilkins JT, Wu JH, Alger HM, Wong SS, Muntner P, American Heart Association Statistics Committee and Stroke Statistics Subcommittee (2017) Heart disease and stroke statistics-2017 update: a report from the American Heart Association. Circulation. 135(10): e146-e603. https://doi.org/10.1161/CIR.0000000000000485

3. Aggeli C, Lagoudakou S, Felekos I, Panagopoulou V, Kastellanos S, Toutouzas K, Roussakis G, Tousoulis D (2015) Two-dimensional speckle tracking for the assessment of coronary artery disease during dobutamine stress echo: clinical tool or merely research method. Cardiovasc Ultrasound 13(1):43. https://doi.org/10.1186/s12947-015-0038-z

4. Yılmaztepe MA, Uçar FM (2018) Layer-specific strain analysis in patients with suspected stable angina pectoris and apparently normal left ventricular wall motion. Cardiovasc Ultrasound 16(1):25. https://doi.org/10.1186/s12947-0180144-9

5. Balfour PC, Gonzalez JA, Kramer CM (2017) Non-invasive assessment of lowand intermediate-risk patients with chest pain. Trends Cardiovasc Med 27(3): 182-189. https://doi.org/10.1016/j.tcm.2016.08.006

6. Choi J-O, Cho SW, Song YB, Cho SJ, Song BG, Lee S-C, Park SW (2009) Longitudinal 2D strain at rest predicts the presence of left main and three vessel coronary artery disease in patients without regional wall motion abnormality. Eur J Echocardiogr 10(5):695-701. https://doi.org/10.1093/ ejechocard/jep041

7. Tsai W-C, Liu Y-W, Huang Y-Y, Lin C-C, Lee C-H, Tsai L-M (2010) Diagnostic value of segmental longitudinal strain by automated function imaging in coronary artery disease without left ventricular dysfunction. J Am Soc Echocardiogr 23(11):1183-1189. https://doi.org/10.1016/j.echo.2010.08.011

8. Geyer H, Caracciolo G, Abe H, Wilansky S, Carerj S, Gentile F, Nesser HJ, Khandheria B, Narula J, Sengupta PP (2010) Assessment of myocardial mechanics using speckle tracking echocardiography: fundamentals and clinical applications. J Am Soc Echocardiogr 23(4):351-369. https://doi.org/1 0.1016/j.echo.2010.02.015

9. Amundsen $\mathrm{BH}$, Helle-Valle $\mathrm{T}$, Edvardsen $\mathrm{T}$, Torp $\mathrm{H}$, Crosby J, Lyseggen $\mathrm{E}$ Støylen A, Ihlen H, Lima JAC, Smiseth OA, Slørdahl SA (2006) Noninvasive myocardial strain measurement by speckle tracking echocardiography: validation against sonomicrometry and tagged magnetic resonance imaging. J Am Coll Cardiol 47(4):789-793. https://doi.org/10.1016/j.jacc.2 005.10.040

10. Castro PL, Greenberg NL, Drinko J, Garcia MJ, Thomas JD (2000) Potential pitfalls of strain rate imaging: angle dependency. Biomed Sci Instrum 36: 197-202

11. Sengupta PP, Tajik AJ, Chandrasekaran K, Khandheria BK (2008) Twist mechanics of the left ventricle: principles and application. JACC CardiovasC Imaging 1(3):366-376. https://doi.org/10.1016/j.jcmg.2008.02.006

12. Biering-Sørensen T, Hoffmann S, Mogelvang R, Zeeberg Iversen A, Galatius S, Fritz-Hansen T, Bech J, Jensen JS (2014) Myocardial strain analysis by 2dimensional speckle tracking echocardiography improves diagnostics of coronary artery stenosis in stable angina pectoris. Circ Cardiovasc Imaging 7(1):58-65. https://doi.org/10.1161/CIRCIMAGING.113.000989

13. Oxborough D, Batterham AM, Shave R, Artis N, Birch KM, Whyte G, Ainslie PN, George KP (2009) Interpretation of two-dimensional and tissue Dopplerderived strain $(\varepsilon)$ and strain rate data: is there a need to normalize for individual variability in left ventricular morphology? Eur J Echocardiogr 10(5):677-682. https://doi.org/10.1093/ejechocard/jep037

14. Hoffmann S, Jensen JS, Iversen AZ, Sogaard P, Galatius S, Olsen NT, Bech J, Fritz-Hansen T, Biering-Sorensen T, Badskjaer J, Pietersen A, Mogelvang R 
(2012) Tissue Doppler echocardiography improves the diagnosis of coronary artery stenosis in stable angina pectoris. Eur Heart J-Cardiovasc Imaging 13(9):724-729. https://doi.org/10.1093/ehjci/jes001

15. Montgomery DE, Puthumana JJ, Fox JM, Ogunyankin KO (2011) Global longitudinal strain aids the detection of non-obstructive coronary artery disease in the resting echocardiogram. Eur Heart J-Cardiovasc Imaging 13(7):579-587. https://doi.org/10.1093/ejechocard/jer282

16. Liang H-Y, Cauduro S, Pellikka P, Wang J, Urheim S, Yang EH, Rihal C, Belohlavek M, Khandheria B, Miller FA, Abraham TP (2006) Usefulness of two-dimensional speckle strain for evaluation of left ventricular diastolic deformation in patients with coronary artery disease. Am J Cardiol 98(12): 1581-1586. https://doi.org/10.1016/j.amjcard.2006.07.038

17. Radwan H, Hussein E (2017) Value of global longitudinal strain by two dimensional speckle tracking echocardiography in predicting coronary artery disease severity. Egyptian Heart J 69(2):95-101. https://doi.org/10.101 6/j.ehj.2016.08.001

18. Caspar T, Samet H, Ohana M, Germain P, El Ghannudi S, Talha S et al (2017) Longitudinal 2D strain can help diagnose coronary artery disease in patients with suspected non-ST-elevation acute coronary syndrome but apparent normal global and segmental systolic function. Int J Cardiol 236:91-94 https://doi.org/10.1016/j.ijcard.2017.02.068

19. H-j Z, Yang X-t, Q-g L, Zhang Y, H-s Z, J-t Y et al (2018) Global longitudinal strain at rest for detection of coronary artery disease in patients without diabetes mellitus. Curr Med Sci 38(3):413-421

\section{Publisher's Note}

Springer Nature remains neutral with regard to jurisdictional claims in published maps and institutional affiliations.

\section{Submit your manuscript to a SpringerOpen ${ }^{\circ}$ journal and benefit from:}

- Convenient online submission

- Rigorous peer review

- Open access: articles freely available online

High visibility within the field

- Retaining the copyright to your article

Submit your next manuscript at $\boldsymbol{\nabla}$ springeropen.com 